after weighing counsel's opinion the committee determined that no further legal action should be taken. The eminent counsel consulted pointed out that "the validity of the power of expulsion does not prevent the by-law complained of being questioned in so far as it purports to impose restrictions upon meetings and discussions, and that the voluminous evidence collected by the plaintiffs shows the existence, in early times at all events, of the rights of the commonalty to be summoned to meet from time to time, and, when so met, of freely discussing all matters concerning the common craft." Counsel further expressed the opinion " that the evidence, however, tends to grow less distinct as time goes on, and that it is questionable whether these rights, though never in terms taken away, had not suffered largely from general encroachments by the governing body and fallen by lapse of time into disuse."

It is now the duty of the special committee to point ont that the expenses of the action at law must be promptly met, so than the four nominal plaintiffs-Messrs. Warwick C. Steele, Wm. Ashton Ellis, Jabez Hogg, and W. G. Dickinson-may be speedily relieved from the responsible position in which the adverse judgment of Mr. Justice Romer places them. The committee, on behalf of the whole body of Members, fully realise and share the plaintiffs' responsibility, and, moreover, consider also that they have a strong moral claim upon the Members of the College generally, and they look with perfect confidence for a willing and substantial response to this appeal.

The exact amount of the costs has not yet been ascertained, but if the President and Council of the College press for their costs, then the committee have reason to believe that the whole will not be less than $£ 2000$. Be this as it may, the Members of the College will, we feel assured, not allow the plaintiffs to suffer, but by generous assistance testify to their courage and self-abnegation displayed in the important contest in which they have been engaged on their behalf. - Signed, on behalf of the Special Committee.

Feb. 22nd, 1892 Geo. DANFord Thomas,

Subscriptions may either be sent direct to Dr. G. Danford Thomas, Park Lodge, Paddington, W., or to the National Bank, Bayswater Branch, W. (Steele v. Savory Fund).

\section{DR. ROOSA'S TREATISE ON DISEASES OF THE EAR.}

To the Editors of THE LANCET.

SIRS,-I crave permission to make a few remarks on your able review in THE LANCET of Feb. 20 th on Dr. St. John Roosa's equally excellent book on "Diseases of the Ear." Your reviewer, no less than the author, has done good service in calling attention to "conclusions which are fearlessly stated," and which, when I read them, appeared to me almost as an echo of opinions which you permitted me to express in THE LANCET of July $6 \mathrm{bh}, 1889$, and April 11th, 1891. If the echoes of your reviewer are re. echoed by your journal from time to time until they reverberate sufficiently to reach the ears of the medical profes. sion, and through their influence the ears of the public, you will, as you have been on former occasions, be the means of exposing and checking abuses that are harmfal alike to the profession and the public. On the subject of electricity (vide review) the author in this edition omits certain paragraphs upon the value of electricity as a diagnostic agent, "which he now frankly confesses have not sufficient basis to be of practical utility." Now (vide THE LANCET, April 11th, 1891), "perhaps because tinnitus, due to degeneration and some other causes, is of a constant character, the kind of electricity which finds favour anongst its advocates is the constant current; but whether this or the interrupted is employed, it is generally the personally conducted and continuous as long as possible." Whether for diagnostic or curative purposes, the results are practically the same; so there is no advantage on dwelling upon the different reasons which prompt its employment.

Again (vide review) : " $\mathrm{He}$ also gives us a plain opinion on the value of operations upon the tympanic membrane and ossicles in non-suppurative affections of the middle ear, and plainly hints at their experimental nature and generally disappointing results." Now, on incision of the tympanic membrane, with division of the tensor tympani (vide THE LANCET, July 6 th, 1889) : "Its history includes a flight of the imagination, a brief notoriety, and a burial in oblivion so rapid as falls to the lot of few achievements in surgery."
Again (vide review): "Dr. Roosa speaks in condemnation of operations upon the nose in cases of deafness, and he shares in the opinion of some others that those who now enthusiastically adopt and advise these operations will in time relinquish them." Now (vide TIIE LANCET, April 1lth, 1891) on removal of the middle turbinated bone: "As a surgical procedure this operation is outside the pale of serious discussion, and I mention it only as an example of a bubble remedy, that the very mention of it may possibly hasten its in evitable bursting."

I have not as yet had the opportunity of seeing this edition of Dr. Roosa's book, though I am familiar with previous editions, but I hope that he may have echoed what $I$ have said on the subjects of so-called artificial ear. drums and the injections of pilocarpine. On the former (vide The LANCET, April 11th, 1891): "Now practically any form of artificial membrane that is advocated presupposes that all perforations which require protection and pressure can have them usefully applied by one for $m$, the fact being that each perforation requires management, to be acquired only by experience, after careful examination, and when any support of the kind is wanted it mugt be regulated by the patient, his sensations being the guide in regarcs to pressure." On the subject of injections of pilocarpine, which were some time ago revived in this country, I say nothing. Professor Politzer, who made the original experi. ments in 1879, disposed effectually of them in THE LANCET of Jan. 3rd, when he spuke of "practitioners who subject their patients to a long and wean isome course of treatment with pilocarpine," and added : "I feel it my duty to say that they are not too conscientious in the discharge of their calling " You will, Sirs, I feel sure, forgive me for occupying so much space in repeating, and so accentuating, these various points, when you reflect, as I hope you will be able to do ere long, that your journal has been. mainly instrumental in puoting limits ao least, if not a full stop, to the employment of some nseless remedies.

I am, Sirs, your obedient servant,

Savile-row, W., Feb. 22nd, 1892. W. B. DALBY.

\section{LARYNGEAL AFFECTIONS AFTER INFLUENZA,}

\section{To the Editors of THE LANCET.}

SIRS, - During an attack of influenza all the effects of catarrhal inflammation may be observed. Most of these effects are so frequently seen as to be familiar to all. There are, however, complications and sequelæ which are less common. Some patients have been attacked with cedema, coming on in some cases suddenly, in others insidionsly. Hæmorrhages from the larynx have been more common and generally very slight. During convalescence ecchymoses and purpuric spots have been observed. Venous congestion, a rare affection in this locality, has been noticed. But the most interesting consequences are neuroses. Tae paralyses which may be seen in catarrhal laryngitis of course form the larger proportion of these neuroses; but this note is intended to draw attention to the sequelæ rather than the complications of influenza. Paralysis commencing in the throat after convalescence and extending to other regions has so precisely simulated that which follows diphtheria as to suggest a doubt as to the nature of the original a tack. But other paralyses, more localised, have also come on af ter the patients had returned to their avocations. The most. commonly affected muscles have been the crico-thyroide: laterales, the thvro-arytænoidei externi et interni, and the ary tænoideus. Thus we get more or less paralysis of adduction, either single or double, with corresponding loss of voice. Almost as frequently the action of the thyro-aryiænoidei interni and the crico-arytænoidei and crico-thyroidei is impaired or abolished; and as the last named is affected by the superior laryngeal nerve, neuroses of sensation as well as motility resulr. Anæsthesia and hyperysthesia of the larynx have also been observed, but the extensive range of normal sensibility in different persons renders it diffenit to demonstrate minor degrees of such deviations. Neuralgia is rare, and I have only met with one case following an attack of the present epidemic. I may mention among sequelse retting in very late choreic movements and spas. modic affections, as well as the stammering of the voral cords described by me in THE LANCET of Nov. 15 th, 1879 These cases are rare. It would appear that these cases of late sequelæ are indications that the effects of inflint $n z a$ remain for a considerable period, and the proportion of 
neuroses shows how profoundly the disease affects the nervous system. - I am, Sirs, yours truly,

Deanery-street, Park-lane, Feb. 22nd, 1892 . Prosser James, M.D.

\section{FEES FOR NOTIFICATION.}

To the Editors of THE $\mathbf{T A N C}$ N.

SIRS,--Having had lately several inquiries as to the result of the appeal in the case of Chisholm $v$. Radcliffe Local board, in which I successfully contended that medical men are by law bound to receive the fee of two shillings and sixpence intact for each notification under the Infectious Diseases Notification Act, 1890, and as others besides my correspondents may desire the same information, I am glad to be able to inform all whom it may concern that the fees, with costs, were paid in fall and no appeal attempted. Consequently, according to Judge Jones's decision, unless the local authorities arrange otherwise, and thus save double postage, medical men can send the notices in unstamped envelopes, and the medical officer is bound to receive them. Should the local authority attempt to deduct the postage from the bill, as they are ill advised by the Local Government Board to do, they can be sued at court for the full fee ; but, if the notices be foolishly prepaid, the stamps cannot be sued for, unless, as I have just said, the authority agreed beforehand to pay. Should the medical officer of health, or such officer as the notice be addressed to, refuse to receive the letter, as was done in nuy case, it is returned to the sender, who should receive it and pay whatever postage is charged, as it will be evidence, should the case come to trial, that he has done the work for which he claims his fee, and in this instance the out-of-pocket stamp value for the returned notice. I am advised that, should any person be so inclined, any local authority refusing to accept delivery of a notice under the Infectious Diseases Notification Act, 1890, whether prepaid or not, is liable to an action at law for ignoring the notice, and thus endangering the health and lives of the community. It is evident, therefore, that for the present, and until the Act is altered, they are on the horns of a dilemma, and medical men are idiotic who put their hands into their own pockets for stamps, to save the rates, when by law they are exempted. - I am, Sirs, yours truly,

KenNeth MACKenzie Chisholi, M.D.

Radcliffe, near Manchester, Feb. 22nd, 1892.

\section{THE DOVER SANITARY AUTHORITY AND INFLUENZA.}

To the Editors of THE LANCET.

SrRS,-In your review of a pamphlet issued by Dr. Sisley I see you refer to the action of the Dover Town Council in a way calcnlated to convey an erroneous impression as to the notice issued by the above-named authority. Allow me to say that this notice was not an empty threat, but was framed and circulated as an educational instrument with two specific objects in view-viz., first, to declare the fact, now pretty clearly established, that influenza is a dangerous infections disease ; and, secondly, to remind people that the Public ${ }^{3}$ Health Act of 1875 provides a method for dealing with persons who, whilst suffering from a dangerous infectious disease, wilfully expose themselves in public places \&c. If no proceedings have hitherto followed the notice in question it is not because the Dover Sanitary Authority has been indulging in a farce, but because no clear case has arisen in which a prosecution could be instituted. Suffice it to add that we believe the notice has not only been of great service, but has answered the purpose for which it was issued, and, further, that the course taken has been so far appreciated that it has been followed by many other sanitary authorities. - I am, Sirs, yours faithfully,

$$
\text { M. K. Roninson, M.D., }
$$

Dover, Feb. 22nd, 1892. Medical Officer of Health for East Kent.

\section{BIRMINGHAM.}

ROM OUR OWN CORRESPONDENT.)

The General Hospital.

A SPECIAL MEETING of the governors of this institution was held on the 22nd inst., for the purpose of considering certain alterations in the laws affecting the honorary medical and surgical staff. Hitherto the terms govern- ing these appointments have heretofore precluded the holding of any office at other hospitals, except those on the consulbing staff. It is proposed to do away with this restriction, so that the holders of appointments at the General Hospital may be eligible for other hospitals, and also that any officer on the staff of other hospitals may be attached to the General Hospital when a vacancy occurs. The removal of this barrier is in keeping with modern ideas, and also places the hospitals of the city on the same level with regard to professional appointments being held simultaneously. The alteration is rendered the more desirable since the staff of the workhouse infirmary can be selected from a wider field, and choice made of candidates engaged in duties of a similar kind at the largest hospitals. The other important alteration is that of the honorary medical and surgical staff each member shall be elected for fifteen years, and shall only once be eligible for reelection for a further term of ten years, but he shall not be eligible for re-election if, being a medical officer, he is six byfive years of uge, or a surgical officer, he is sixty years of age, and he shall vacate office on attaining that age. None of the officers, honorary or assistant, shall hold any other office which interferes with the efficient discharge of his. duties at the hospital. These, with some minor details, commend themselves on the ground of progress and justice, and no doubt will be ratified at the subsequent meeting to be held shortly.

\section{The Llandudno Convalescent Home.}

This home is to be opened on May 7 th, so the Hospital Saturday delegates were informed at a social meeting held on the $23 \mathrm{rd}$ inst. It was stated also that a magazine was about to be started in support of the Hospital Saturday movement. The premises at Tyn-y-Coed were about to. be furnished, some stock had been taken over, and the prospects were bright for the future working of the estate. The promoters of this valuable movement may be congratulated upon the near approach of success to their efforts.

\section{The General Dispensary.}

Alderman Clayton presided at the annual meeting held on the 24 th inst. The report stated that the income for the year had been $£ 783917 \mathrm{~s}$, while a balance of $£ 356$ 11s. $5 d$. had been carried forward. The totai number of patients admitted during the year by tickets had been 29,534 , an increase of 3504 over the previous year. The average cost of patients was $3 s, 6 \frac{3}{4} d$, as ahgainst 3s. $11 \frac{3}{4} \mathrm{~d}$. Teeth and accident cases had also been 3935. The amount of $£ 11512 s .2 d$, was acknowledged from the Hospital Saturday Fund. There had been an overdraf of $£ 719 s .8 \%$. on the relief fund, which was a matter of regret, as it crippled the medical officer's work. After some discus. sion about the tickets, the usual votes of thanks were passed. Feb. 25th.

\section{LIVERPOOL.}

(FroM OUR OWN CORRESPONDENT.)

\section{The Influenza and the Death-rate.}

CASEs of influenza have become less frequent of late, and the death-rate has fallen to a ratio nearer the normal one. Still one hears of professional and lay friends being down with the disease, which has been prevalent here as elsewhere, and the fatalities of the winter from it, its accompaniments, and from other causes incidental to severe weather, have been grievously numerous. The gaps which have been made in the ranks of old citizens exceed those made by any previous winter.

\section{Presentation to a Local Coroner.}

Allusion was made in a previous letter to the fact that Mr. Henry Churton, the medical coroner for the Chester district of the county of Cheshire, and for the borough of Birkenhead, had completed his fiftieth year of office as coroner. Mr. Churton was appointed in" 1841 , when Birkenhead, Crewe, and other important centres with large populations were villages. He was then twenty.eight; bence he has now attained his seventy-eighth year, and still possesses excellent health. He had lately the misfortune to suffer a severe bereavement in the death of his wife. Advantage was recently taken by some residents at Birkenhead to present him with a silver bowl as a token of the esteem in which he was held in that town. In retarn. 